\title{
Dendromonocotyle colorni sp. n. (Monogenea: Monocotylidae) from the skin of Himantura uarnak (Dasyatididae) from Israel and a new host record for $D$. octodiscus from the Bahamas
}

\author{
Leslie A. Chisholm ${ }^{1}$, Ian D. Whittington ${ }^{1}$ and Graham C. Kearn ${ }^{2}$ \\ ${ }^{1}$ Department of Microbiology and Parasitology, The University of Queensland, Brisbane, Queensland 4072, Australia; \\ ${ }^{2}$ School of Biological Sciences, University of East Anglia, Norwich, NR4 7TJ, UK
}

Key words: Monogenea, Monocotylidae, Dendromonocotyle colorni, Dasyatididae, Himantura uarnak, parasite development, adaptive response, Israel

\begin{abstract}
Dendromonocotyle colorni sp. n. (Monogenea: Monocotylidae) is described from the dorsal skin surface of two specimens of Himantura uarnak (Forsskål) kept at the Eilat Underwater Observatory in Israel. Dendromonocotyle colorni is distinguished from the other eight species in the genus by the morphology of the terminal papillar sclerite on the haptor, the distal portion of the male copulatory organ and the morphology of the vagina. The development of the male copulatory organ is detailed for D. colorni and the adaptations of species of Dendromonocotyle to life on the dorsal skin surface of rays are discussed. Dendromonocotyle octodiscus Hargis, 1955 was identified from the dorsal skin surface of the southern stingray Dasyatis americana Hildebrand et Schroeder off Bimini, Bahamas and represents a new host record.
\end{abstract}

Species of Dendromonocotyle Hargis, 1955 are the only monocotylids found on the skin of rays. There are currently eight valid species of Dendromonocotyle and they can be differentiated most readily from other members of the Monocotylidae Taschenberg, 1879 by their habitat and by the presence of a dendritic gut which has pigment associated with it (e.g. Kearn 1979). Chisholm and Whittington (1995) revised the genus and noted that hamuli are present in some species, but are absent in others.

We have since received specimens of Dendromonocotyle from the skin of two reticulate rays, Himantura uarnak (Forsskål), kept at the Eilat Underwater Observatory in Israel and from the skin of a specimen of Dasyatis americana Hildebrand et Schroeder, which was the subject of a study of cleaner fish/host interactions by Snelson et al. (1990) near Bimini, Bahamas. Neither of these hosts has been reported to harbour Dendromonocotyle spp. and therefore a detailed study was made to identify the parasites. In addition, the specimens of $H$. uarnak from Israel carried a range of juvenile and adult parasites and offered an opportunity to trace the development of the male copulatory organ.

\section{MATERIALS AND METHODS}

Two specimens of Himantura uarnak (identified by Dr. D. Golani) caught in the Gulf of Eilat, along the Sinai coast and held in a saltwater pond at Eilat Underwater Observatory, Israel were examined for ectoparasites. The dorsal skin surface was parasitised by monogeneans which were removed by dipping the rays in fresh water for one minute. The monogeneans were flattened under slight coverslip pressure in $10 \%$ buffered neutral formalin (BNF) at room temperature or were preserved unflattened in either $10 \% \mathrm{BNF}$ or Bouin's fixative. Some flattened specimens were stained with Semichon's carmine or haematoxylin or left unstained. All specimens were dehydrated in an ethanol series, cleared in cedarwood oil and mounted in Canada balsam.

Some unflattened specimens were processed for scanning electron microscopy (SEM). Specimens were post-fixed in osmium tetroxide in $0.1 \mathrm{M}$ cacodylate buffer for $2 \mathrm{~h}$ and dehydrated in a graded ethanol series. These specimens were soaked in $50 \%$ hexamethyldisilazine (HMDS) for $2 \mathrm{~h}$, then in pure HMDS for $8 \mathrm{~h}$ and dried by allowing the HMDS to evaporate. Specimens were mounted on an aluminium stub, sputter coated with gold and examined with a JEOL 6300 Field Emission scanning electron microscope operating between 5 and $7 \mathrm{kV}$.

Preserved adult specimens were examined using a compound photomicroscope equipped with phase contrast optics and drawings were made with the aid of a drawing tube. Measurements of all specimens were made using a computerised digitising system similar to that described by Roff and Hopcroft (1986). All measurements are given in $\mu \mathrm{m}$ as the mean followed in parentheses by the range and the number of structures measured. Measurements of the male copulatory organ include the curves. All body length measurements quoted in this study exclude the haptor. Haptoral terminology follows that of Chisholm and Whittington (1995).

For comparative purposes, type material of Dendromonocotyle ardea and D. octodiscus (see Chisholm and Whittington [1995] for the list of accession numbers) was obtained from The Queensland Museum (QM), P.O. Box 3300, South Brisbane, Queensland 4101, Australia and The United States National Parasite Collection (USNPC), Beltsville, MD 20705, USA, respectively. Type material of the new species is 
deposited in the QM, in The Hebrew University Scientific Collections (HUJ), Section of Invertebrates, The Department of Evolution, Systematics and Ecology 91904 Jerusalem, Israel and in the Institute of Parasitology (IPCR), Academy of Sciences of the Czech Republic, Branišovská 31, 37005 České Budějovice, Czech Republic. Voucher specimens of $D$. octodiscus are deposited in the QM.

\section{RESULTS}

M o n o c oty 1 i n a e Taschenberg, 1878

Dendromonocotyle Hargis, 1955

\section{Dendromonocotyle colorni $\mathrm{sp} . \mathrm{n}$.}

Figs. 1-4

Description. Dendromonocotyle sensu Chisholm and Whittington 1995. Description and measurements based on 15 flattened sexually mature specimens. Body 2608 (1436-3750, $\mathrm{n}=15)$ long, $2100(906-3046, \mathrm{n}=15)$ wide at level of ovary (Fig. 1). Haptor circular, diameter 1867 (1184-2886, $\mathrm{n}=11$ ); divided into 8 loculi (Figs. 1, 2A). Haptor diameter represents $77 \%$ of body length (range $70-84 \%$; SE $\pm 0.05 \%$ ); ratio similar in juvenile specimens. Hamuli (Fig. 3D) 53 (43-64, $\mathrm{n}=7$ ) long, located in outer ring septum associated with septal pair 1. Fourteen hooklets (Fig. 3E) $12(11-14, \mathrm{n}=14)$ long, distributed symmetrically in marginal valve between every 4 papillae (Fig. 1). Haptoral rim with 56 marginal papillae (Figs. 1, 2A). Eight papillae associated with posterior and posterolateral loculi; 6 papillae associated with anterolateral and anterior loculi (Fig. 1). Marginal papillae with 3 sclerites (Figs. 1, 2C); terminal papillar sclerite distinct (Figs. 2C, 3A), other 2 sclerites similar to sclerites on radial septa (Fig. 3B). Septal sclerite morphology as shown (Figs. 2C, 3B); sclerites at junction of radial septum and inner ring septum with 3 arms (Fig. 3C). No tripartite sclerites at junction of radial septum and outer ring septum.

Mouth ventral, subterminal (Figs. 1, 2B). Subterminal groove on tegument anterior to mouth (Figs. 1, 2B). Six distinct anterolateral gland duct openings on either side of head (Figs. 1, 2B, 2D); containing needle-like secretion. Two pairs of eyespots dorsal to pharynx. Pharynx 210 (107-301, $\mathrm{n}=14)$ long, 154 (79-237, $\mathrm{n}=$ 14) wide. Intestinal diverticula extending from level anterior to pharynx to posterior margin of body proper (Fig. 1). Pigment present, associated with lining of intestinal diverticula, in all specimens collected, including juveniles.

Testis single. Vas deferens arises from left side of testis, runs anteriorly dorsal to vagina, loops twice, before narrowing and curving to right side of body. Vas deferens inflates to form seminal vesicle then narrows, entering ejaculatory bulb posteriorly (Fig. 1). Ejaculatory bulb $198(127-266, \mathrm{n}=15)$ long, $170(117-222, \mathrm{n}=$ 15) wide. Male copulatory organ sclerotised; straight in sexually mature specimens (Figs. 1, 4C); total length in

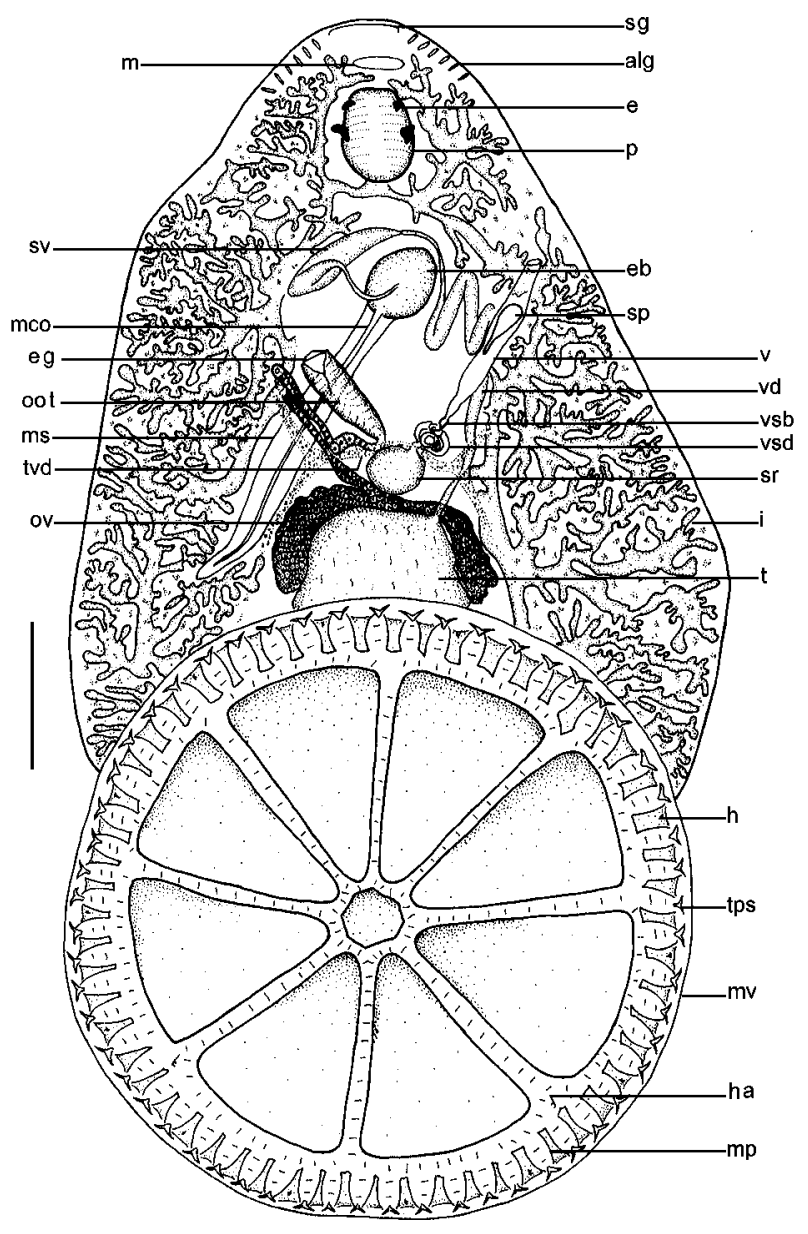

Fig. 1. Dendromonocotyle colorni sp. n. Full-body composite drawing, ventral view. Note: for clarity, intestinal diverticula surrounding and overlying reproductive organs not drawn. Abbreviations: alg - anterolateral gland duct opening with needle-like secretion; e - eyespot; eb - ejaculatory bulb; eg - egg; h - hooklet; ha - hamulus; i - intestinal diverticulum; m - mouth; mco - male copulatory organ; $\mathrm{mp}$ - marginal papilla; ms - muscular sheath surrounding male copulatory organ; mv - marginal valve; oot - oötype; ov - ovary; $\mathrm{p}$ - pharynx; sg - subterminal groove; sp - spermatophore; sr - seminal receptacle; sv - seminal vesicle; $\mathrm{t}$ - testis; tps - terminal papillar sclerite; tvd - transverse vitelline duct; $\mathrm{v}$ - muscular portion of vagina; vd - vas deferens; vsb - sclerotised bulb of vagina; vsd - sclerotised coiled duct of vagina. Scale bar $=500 \mu \mathrm{m}$.

sexually mature specimens $867(817-915, \mathrm{n}=14)$. Distal portion of male copulatory organ bearing unique sclerotised flange and sclerotised spiral filament in region of flange and on distal end (Fig. 4C). Entire length of male copulatory organ surrounded by muscular sheath (Figs. 1, 2D, 2E). Muscular sheath bears opening at distal end presumably through which sclerotised organ protrudes (Fig. 2E).

Ovary bilobed with one lobe on either side of testis (Fig. 1); fusing medially; single branch loops right intestinal caecum dorsoventrally and forms oviduct. 

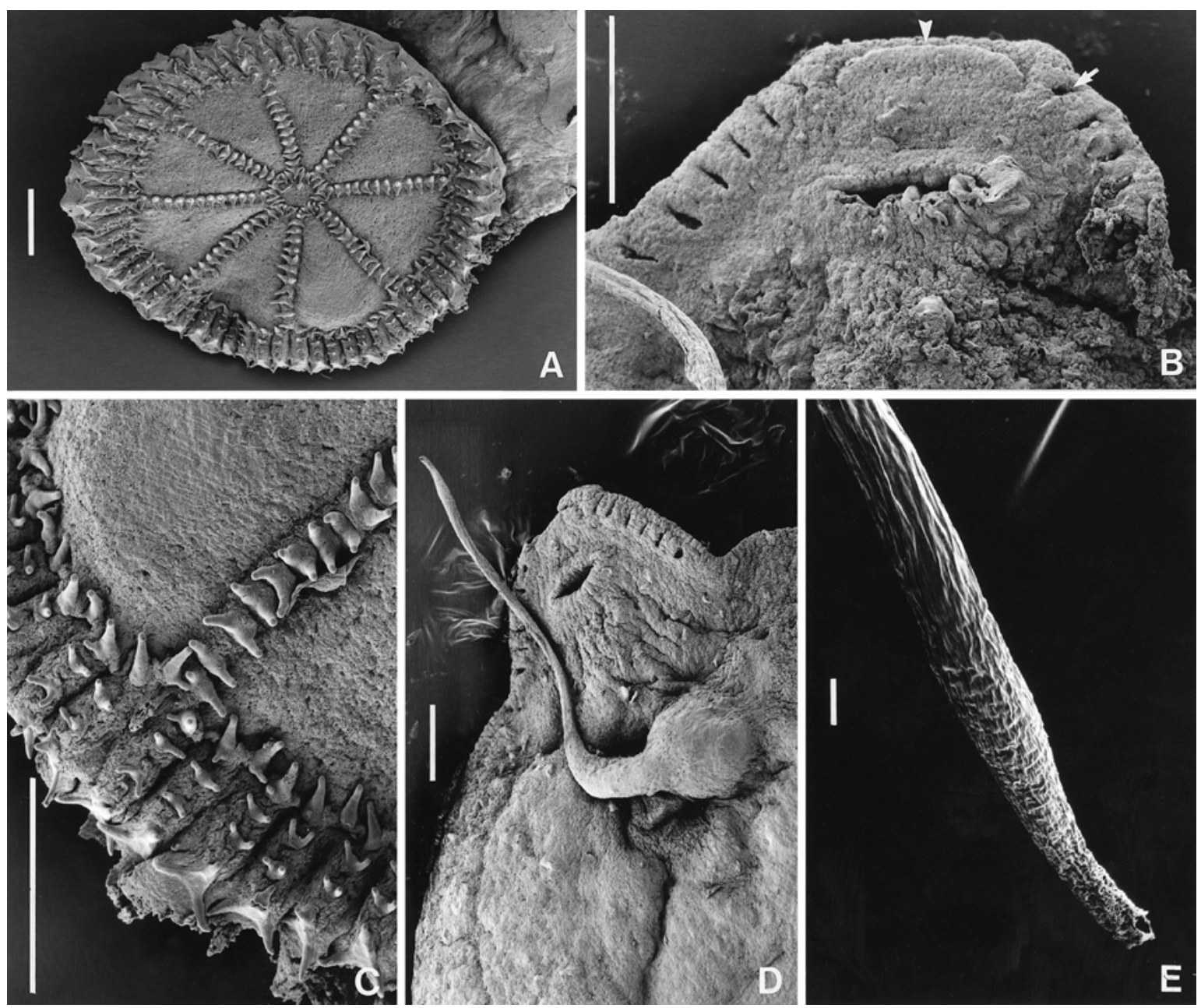

Fig. 2. Scanning electron micrographs of Dendromonocotyle colorni sp. n. A - Haptor, ventral view. B - Anterior end showing anterolateral gland duct openings (arrow), subterminal groove (arrowhead) and mouth. $\mathbf{C}-$ Close up of haptor showing terminal papillar and septal sclerites. D - Male copulatory organ protruding from body and surrounded by muscular sleeve. $\mathbf{E}-$ Distal end of male copulatory organ showing opening at end of muscular sheath. Scale bars: A-D $=100 \mu \mathrm{m} ; \mathrm{E}=10 \mu \mathrm{m}$.

Oviduct receives common vitelline duct and duct from seminal receptacle. Ovovitelline duct enters oötype. Oötype $203(159-253, \mathrm{n}=5)$ long. Mehlis glands not observed. Vaginal pore on left side of body at level of ejaculatory bulb. Vagina divided into 3 distinct regions; distal region long and muscular; narrows to form distinct sclerotised bulb; tightly coiled sclerotised duct arises from bulb (Fig. 1). Coiled duct enters spherical seminal receptacle diameter $212(177-273, \mathrm{n}=5)$. Sclerotised spermatophore (Figs. 1, 3F) 222 (208-245, $\mathrm{n}=3)$ long, $109(107-111, \mathrm{n}=2)$ wide, observed in vagina of 3 mature specimens.

Vitellarium inconspicuous, largely obscured by extensive pigmented intestinal diverticula; extending from level of mouth to posterior portion of body proper. Transverse vitelline duct at level of anterior portion of seminal receptacle; common vitelline duct joining oviduct. Egg tetrahedral (Fig. 3G); side length 79 (60-
$92, \mathrm{n}=12$ ) (measured within oötype of flattened specimens).

T y p e h o s t: Himantura uarnak (Forsskål).

T y p e 1 o c a 1 i t y : Eilat Underwater Observatory, Israel.

S i te o n host: Dorsal skin surface.

I $\mathrm{n} f \mathrm{e} \mathrm{ct}$ i o $\mathrm{n}$ det a i l s: Two rays infected with numerous parasites.

E t y m o 1 o g y : The species is named after Dr. Angelo Colorni who collected the monogeneans.

M a te r i a 1 e x a m in ed: Holotype QM G 218063, 25 paratypes QM G 218069-93; 2 paratypes IPCR M-365, 9 paratypes HUJ-MONO 5-13.

Remarks. The morphology of the haptoral terminal papillar sclerite, the form of the distal region of the male copulatory organ and the morphology of the vagina distinguish Dendromonocotyle colorni from the other eight members of the genus. 


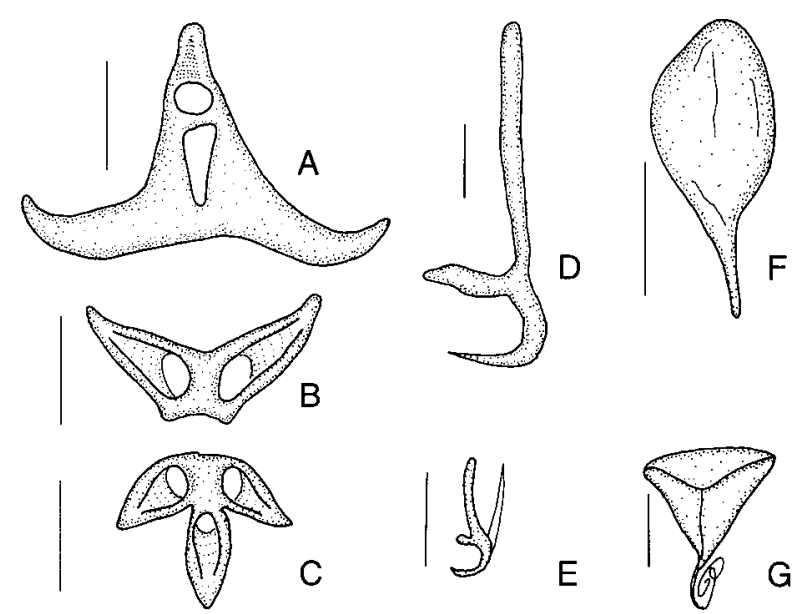

Fig. 3. Dendromonocotyle colorni sp. n. A - Haptoral terminal papillar sclerite. B - Haptoral septal sclerite. C - Septal sclerite at junction of radial septum and inner ring septum. D - Hamulus. E - Hooklet and domus. F - Sclerotised spermatophore. $\mathbf{G}-$ Egg. Scale bars: A-E $=10 \mu \mathrm{m} ; \mathrm{F}=100$ $\mu \mathrm{m} ; \mathrm{G}=50 \mu \mathrm{m}$.
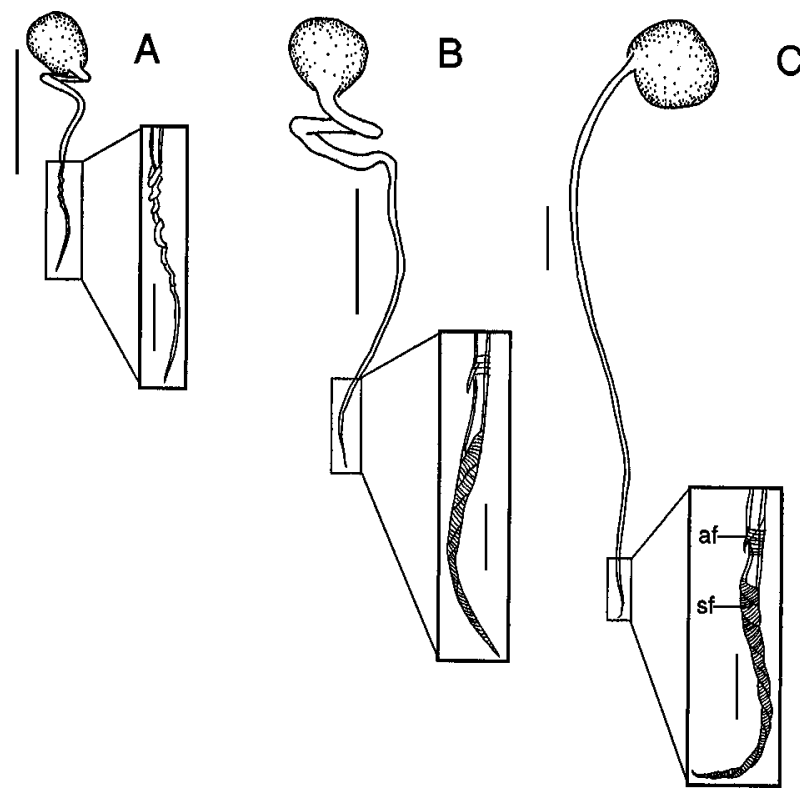

Fig. 4. Development of male copulatory organ (MCO) of Dendromonocotyle colorni $\mathrm{sp}$. $\mathrm{n}$. Insets are enlargements of distal end to illustrate detailed morphology including sclerotised accessory flange (af) and spiral filament (sf). A - Juvenile specimen (total MCO length $223 \mu \mathrm{m}$; body length $519 \mu \mathrm{m}$ ). Distal end of MCO loosely coiled, sclerotised accessory flange and spiral accessory filament absent. B - Juvenile specimen (total MCO length $454 \mu \mathrm{m}$; body length $825 \mu \mathrm{m}$ ). Distal end of MCO more tightly coiled, sclerotised accessory flange and spiral accessory filament present but not fully developed. C Sexually mature specimen, total MCO length $898 \mu \mathrm{m}$, body length $1596 \mu \mathrm{m}$. Distal end of MCO tightly coiled and sclerotised accessory flange and spiral accessory filament fully developed. Scale bars for whole structures $=100 \mu \mathrm{m}$; magnified insets $=25 \mu \mathrm{m}$.
Development and morphology of the male copulatory organ. Worms ranging from small juveniles to large sexually mature specimens as described above were collected. Body length and total length of the sclerotised male copulatory organ were measured for each specimen. For juvenile specimens of D. colorni, there is a significant linear relationship $\left(R^{2}=0.97\right.$; $\mathrm{p}<0.0001$ ) between body length and male copulatory organ length (Fig. 5). However, once the parasites attain a body length of approximately $1500 \mu \mathrm{m}$, they become sexually mature (assessed by the presence of reproductive organs, vitellarium and sometimes an egg in the oötype) and the relationship between body length and male copulatory organ length disappears (Fig. 5). The parasites continue to grow after they reach sexual maturity and the body increases in length by a factor of more than two, but there is no further increase in the length of the male copulatory organ (Fig. 5).

The morphology of the male copulatory organ changes as the parasites mature. In juvenile specimens, the male copulatory organ loops once soon after it exits the ejaculatory bulb (Figs. 4A, 4B). In mature specimens, the male copulatory organ straightens and the loop disappears (Fig. 4C). The distal end of the male copulatory organ also undergoes a distinct developmental change. In a small juvenile specimen of body length $519 \mu \mathrm{m}$, the distal end of the male copulatory organ forms a loose spiral and there is no sclerotised accessory flange nor spiral filaments (Fig. 4A). The male copulatory organ in a specimen of body length $825 \mu \mathrm{m}$ forms a tighter spiral and a flared accessory filament is present together with a spiral filament (Fig. 4B). The distal end of the male copulatory organ of a sexually mature specimen with a body length of $1596 \mu \mathrm{m}$ forms a very tight spiral and bears both the flared accessory and spiral filaments (Fig. 4C).

\section{Dendromonocotyle octodiscus Hargis, 1955}

Remarks. Snelson et al. (1990) found specimens of a Dendromonocotyle sp. on the skin of Dasyatis americana after a series of observations on cleaner fish/ray host interactions near Bimini, Bahamas. The monogeneans reported were not identified to species by Snelson et al. (1990), but some were sent to us for examination. Pigment is present in the gut caeca of these specimens. The morphology of the haptoral terminal papillar sclerite and the distal portion of the male copulatory organ is consistent with that of Dendromonocotyle octodiscus which was redescribed and illustrated by Chisholm and Whittington (1995) and we consider that these specimens are D. octodiscus. This represents a new host record for this monocotylid species. Dendromonocotyle octodiscus has now been reported from four different host species including Dasyatis say (Lesueur) (see Hargis 1955), D. marmorata (Steindacher) (Dasyatididae) (see Euzet and Maillard 1967), Urolophus jamaicensis (Cuvier) 
(Urolophidae) (see Chisholm and Whittington 1995) and D. americana (present study). Two voucher specimens of Dendromonocotyle octodiscus from Dasyatis americana off Bimini, Bahamas have been deposited (QM G 218094-95).

\section{DISCUSSION}

There are now nine species of Dendromonocotyle including D. akajeii Ho et Perkins, 1980, D. ardea Chisholm et Whittington, 1995, D. californica Olson et Jeffries, 1983, D. centrourae Cheung et Whitaker, 1993, D. colorni, D. cortesi Bravo-Hollis, 1969, D. kuhlii Young, 1967, D. octodiscus and D. taeniura Euzet et Maillard, 1967. Previously, hamuli were believed to be absent from all members of the genus, but Chisholm and Whittington (1995) found hamuli in D. akajeii, D. ardea and $D$. californica and revised the generic diagnosis to include this character. We have also found hamuli in $D$. colorni.

Olson and Jeffries (1983) used the presence of "head organs" in their key to species of Dendromonocotyle, but Chisholm and Whittington (1995) stated that "head organs" or anterior gland duct openings were difficult to see in some species of Dendromonocotyle. Six pairs of anterolateral gland duct openings in the form of slit-like apertures are prominent in whole mounts (Fig. 1) and in SEM preparations (Figs. 2B, 2D) of D. colorni. The secretion contained inside these openings appears needle-like, but the glands that produce this secretion and ducts that lead to the apertures could not be traced in mounted material. Whittington and Cribb (2001) have noted that an elongate secretion, which looks needlelike under the light microscope, is the dominant anterior adhesive secretion in most monopisthocotylean monogeneans. Transmission electron microscopy reveals that this secretion is an electron dense rod-shaped body. In monopisthocotyleans studied so far, a second adhesive secretion, usually granular in structure, may also be present (see Whittington and Cribb 2001). We did not observe any granular secretory products at the anterior region of $D$. colorni, but this should be verified in the future by examining live material.

Chisholm and Whittington (1995) presented the developmental sequence for the sclerotised male copulatory organ in $D$. ardea showing that both the proximal and distal portions of the male copulatory organ undergo distinct changes. We have determined that the same is true for the male copulatory organ of $D$. colorni. In juvenile specimens of $D$. colorni, the elongate male copulatory organ has a single proximal loop (Figs. 4A, 4B) which permits the parasite to accommodate the organ in its relatively small body. As the parasite grows, the male copulatory organ straightens (Fig. 4C). We have determined that the increase in the length of the body and of the male copulatory organ is directly proportional in juvenile parasites (Fig. 5). However,

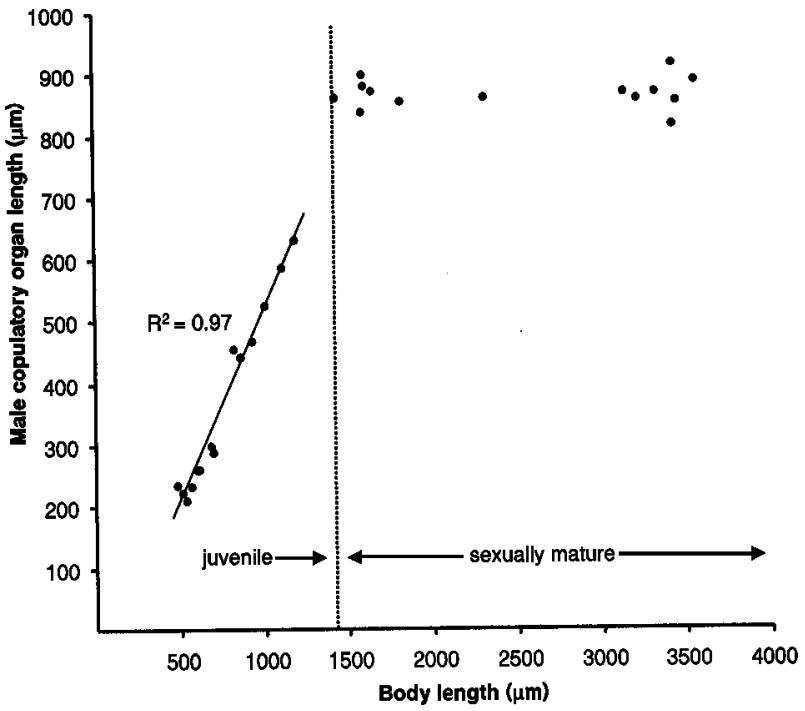

Fig. 5. Scatterplot to illustrate relationship between body length and length of male copulatory organ. Note linear relationship between body length and male copulatory organ length in juvenile specimens; this relationship is lost when the parasites reach sexual maturity (at a body length of approximately $1500 \mu \mathrm{m})$.

once specimens reach sexual maturity, although the body length continues to increase, the length of the male copulatory organ remains unchanged (Fig. 5).

Spermatophores were noted previously in half of the described species of Dendromonocotyle (see Chisholm and Whittington 1995). We have also found spermatophores in the vagina of a number of specimens of $D$. colorni. How these structures are formed and whether they are extruded along the length of the male copulatory organ or only from the distal tip is unknown (Chisholm and Whittington 1995). Studies of live worms to observe mating or spermatophore production would be fruitful.

Chisholm and Whittington (1995) demonstrated that the shape of the distal portion of the male copulatory organ mirrored the shape of the proximal portion of the vagina in most species of Dendromonocotyle. They hypothesised that this may facilitate mate recognition but it is also possible that this tight fit may help prevent separation of mating individuals during sperm exchange. Observations on mating in Dendromonocotyle are required before further comments can be made regarding the mechanisms that operate. The shape of the distal portion of the male copulatory organ of $D$. colorni does not appear to correspond closely with the shape of the vagina. However, the proximal portion of the vagina is sclerotised and highly coiled. This character is unique to $D$. colorni and the significance, if any, of this difference is unknown. It is noteworthy that some species in the sister group Monocotyle Taschenberg, 1878 also have a long male copulatory organ and a 
highly coiled section of the vagina (see Chisholm 1998). Therefore, this arrangement appears to have arisen a number of times in the Monocotylidae.

Species of Dendromonocotyle are the only monocotylids that live on the skin of rays and they appear to have evolved a number of adaptations in response to living on this unprotected habitat. These parasites are exposed to strong water currents as the ray swims and effective attachment to the host by the haptor is paramount. This may account for the increased haptor size in $D$. colorni. The haptor of $D$. colorni represents on average $77 \%$ of the body length in both juveniles and adults and therefore, a significant proportion of the total surface area of the worm is attached to the host.

Rays visit cleaning stations regularly and therefore in addition to the hazards of strong water currents, the skin-dwelling Dendromonocotyle may also be exposed to predation by cleaner organisms. Snelson et al. (1990) studied the behaviour of the southern stingray, Dasyatis americana, at cleaning stations and its interactions with cleaner fish near Bimini, Bahamas. During stationary cleaning events the rays assumed a characteristic posture, balancing on their pectoral fins and elevating their rostrum and tail off the bottom. The skin surfaces were cleaned by the cleaner wrasse, Thalassoma bifasciatum (Bloch), for one to $26 \mathrm{~min}$ on each occasion (Snelson et al. 1990). One of the rays examined after it had been cleaned had unidentified Dendromonocotyle specimens concentrated on the dorsal surface of the rostrum (Snelson et al. 1990). No remnants of monogeneans were found in the gut contents of the cleaner wrasse and this suggests that the cleaner fish may have overlooked the worms. Previously, Kearn (1979) determined that the pigment in the gut of $D$. kuhlii is probably derived from host skin tissue on which the parasite feeds. He noted that pigment in the highly branched gut made the parasites difficult to see and may camouflage the monogeneans and protect them from cleaner organisms. The study by Snelson et al. (1990) supports this assumption, but they did not state whether the Dendromonocotyle specimens they found were pigmented. In the present study, we have identified the specimens recovered by Snelson et al. (1990) as D. octodiscus and have verified the presence of pigment associated with the gut. Pigmentation has been observed in the body of many other monogenean species with examples recorded from the Anoplodiscidae, Capsalidae and Dactylogyridae (see Deveney and Whittington 2001). The presence of pigment in such a wide range of monogeneans may indicate that predation pressure is a strong evolutionary force that has stimulated body pigmentation as an adaptive response.

Acknowledgements. We thank Drs. M. Bryant (QM) and J.R. Lichtenfels and P. Pilitt (USNPC) for the loan of specimens. We are indebted to Dr. A. Colorni from the National Centre for Mariculture, Israel Oceanographic and Limnological Research Ltd who collected the specimens of Dendromonocotyle colorni and Dr. D. Golani, Department of Evolution, Systematics and Ecology, The Hebrew University of Jerusalem, Israel for identifying the two specimens of Himanura uarnak. We are grateful to Dr. F. Snelson who searched his laboratory and sent us specimens of $D$. octodiscus. SEM was done by Mr. M. Deveney at the Centre for Microscopy and Microanalysis at The University of Queensland and we are grateful to the Director and staff for assistance and access to their facilities. Support for LAC and IDW was provided by an Australian Research Council large grant (No. A19801424) for 1998-2000.

\section{REFERENCES}

CHISHOLM L.A. 1998: A revision of Monocotyle Taschenberg, 1878 (Monogenea: Monocotylidae) with descriptions of three new species from Australia. J. Nat. Hist. 32: 12591290.

CHISHOLM L.A., WHITTINGTON I.D. 1995: A revision of Dendromonocotyle Hargis, 1955 (Monogenea: Monocotylidae) with a description of a new species from Pastinachus sephen (Forsskål) (Myliobatiformes: Dasyatididae) from the Great Barrier Reef, Australia. J. Nat. Hist. 29: 1093-1120.

DEVENEY M.R., WHITTINGTON I.D. 2001: A technique for preserving pigmentation in some capsalid monogeneans for taxonomic purposes. Syst. Parasitol. 48: 31-35.

EUZET L., MAILLARD C. 1967: Parasites de poissons de mer ouest-africains. VI. Monogènes de sélaciens. Bull. Inst. Fr. Afr. Noire, Ser A. 29: 1435-1493.

HARGIS W.J., Jr. 1955: Monogenetic trematodes of Gulf of Mexico fishes. Part V. The superfamily Capsaloidea. Trans. Am. Microsc. Soc. 74: 203-225.
KEARN G.C. 1979: Studies on gut pigment in skin-parasitic monogeneans, with special reference to the monocotylid Dendromonocotyle kuhlii. Int. J. Parasitol. 9: 545-552.

OLSON A.C., Jr., JEFFRIES M. 1983: Dendromonocotyle californica sp. n. (Monogenea: Monocotylidae) from the bat ray, Myliobatis californica, with a key to species. J. Parasitol. 69: 602-605.

ROFF J.C., HOPCROFT R.R. 1986: High precision microcomputer based measuring system for ecological research. Can. J. Fish. Aquat. Sci. 43: 2044-2048.

SNELSON F.F., Jr., GRUBER S.H., MURRU F.L., SCHMIDT T.H. 1990: Southern stingray, Dasyatis americana: host for a symbiotic cleaner wrasse. Copeia, 1990: 961-965.

WHITTINGTON I.D., CRIBB B.W. 2001: Adhesive secretions in the Platyhelminthes. Adv. Parasitol. 48: 101224.

Accepted 24 July 2000 